\title{
CONSCIENTIZAÇÃO DA POSTURA CORPORAL EM PROFESSORES DA REDE PÚBLICA DE ENSINO
}

\author{
Magda Campos Curcino, Larissa Ruiz Teixeira, Thaís Delgado Volpe, Maria Rita Masselli \\ Universidade Estadual Paulista - FCT/UNESP. Departamento de Fisioterapia, Presidente Prudente - SP. Programa \\ Núcleo de Ensino. E-mail: magda im@hotmail.com
}

\section{RESUMO}

No contexto de trabalho em que o professor se insere na rede publica atualmente, se reúnem: condição de trabalho precário, desvalorização profissional, expansão das funções, entre outros, levando a uma sobrecarga emocional e física desses profissionais. Isto pode se refletir em sua relação com os alunos, pais dos alunos e comunidade, podendo gerar efeitos negativos em sua saúde. Assim, o objetivo do estudo foi verificar a influência da Terapia de Consciência Corporal (TCC) nas variáveis: percepção da consciência corporal e nível de ansiedade e depressão em professores da rede pública. Participaram 11 professores, os quais foram avaliados antes e após as TCC. Foram realizados 12 sessões de TCC, de 50 minutos, uma vez por semana. Verificou-se uma melhora na percepção da consciência corporal em todos os professores. No nível de ansiedade e depressão não houve uma melhora significativa.

Palavras-chave: consciência corporal, ansiedade, depressão, professores.

\section{BODY AWARENESS ATTITUDE IN TEACHERS NETWORK PUBLIC EDUCATION}

\begin{abstract}
In the work context in which the teacher enters the network currently publishes, gather: condition of precarious work, professional devaluation, expansion of functions, among others, leading to an emotional and physical burden of these professionals. This may be reflected in their relationship with students, parents of students and the community, which can generate negative effects on your health. The objective of the study was to verify the influence of Body Awareness Therapy (CBT) in variables: perception of body awareness and level of anxiety and depression in public school teachers. 11 teachers who were evaluated before and after the TCC participated. 12 CBT sessions once a week were performed, 50 minutes. There was an improvement in the perception of body awareness in all teachers. The level of anxiety and depression did not improve significantly.
\end{abstract}

Keywords: body awareness, anxiety, depression, teachers.

\section{INTRODUÇÃO}

O papel do professor vem sofrendo mudanças com o passar do tempo, eles tiveram que assumir funções que vão além de ensinar e transmitir conhecimentos. Esses profissionais sofrem com a diminuição do reconhecimento e respeito dentro da sala de aula; desinteresse por parte dos alunos levando a um aumento da cobrança pessoal em tornar a aula mais interessante e envolvente; necessidade de adaptação e inclusão da tecnologia no meio escolar; presença de 
ruídos externos e internos á sala causando desconforto vocal por elevação da voz; entre outros (SMITH et al., 1998; PEREIRA; SANTOS; VIOLA et al., 2000; SIMÕES, 2000; DUFFY; HAZLETT, 2004; ARAÚJO et al., 2005).

A presença de fatores insatisfatórios nesta classe trabalhadora, fez com que vários estudos incluíssem os professores numa doença denominada Síndrome de Burnout (SB) que, no Brasil, é conhecida como Síndrome do Esgotamento Profissional. Essa patologia é resultado do estresse crônico típico do cotidiano de trabalho, principalmente quando neste existem excessiva pressão, conflitos, poucas recompensas emocionais e pouco reconhecimento (Harrison, 1999; Charlotto; Palazzo, 2006; Charlotto, 2011), sendo constituído por três dimensões: Exaustão Emocional, Despersonalização e Baixa Realização Profissional. A profissão docente é considerada pela Organização Internacional do Trabalho (OIT), como uma das mais estressantes, com forte incidência de elementos que conduzem à SB (GIL-MONTE, 2008). A insatisfação pode fragilizar o indivíduo, tornando-o susceptível ao adoecimento. As manifestações sintomáticas variam desde um sentimento de insatisfação, frustração, chegando até uma angústia difusa e um profundo sentimento de culpa e impotência. O sofrimento é uma reação inconsciente devido à organização do trabalho, que surge quando a representação do trabalho é penosa, constituindo-se numa mediação entre a saúde mental e as descompensações psicopatológicas (DEJOURS, 1994).

De acordo com os fatos anteriormente citados, há uma reflexão sobre o estresse durante a vida profissional, conflitos na esfera psicocorporal e reflexos em suas vidas sociais. Neste contexto, esta pesquisa foi relevante para a compreensão dos fatores associados à profissão e para que estratégias de intervenções mais eficazes possam ser elaboradas.

O trabalho em questão procurou tratar indivíduos de uma maneira global, criando uma interdependência entre o corpo físico e mental. Sabe-se que a ansiedade e a depressão têm causas tanto somáticas, quanto psíquicas que influenciam direta ou indiretamente a consciência que cada indivíduo possui de seu corpo, sendo esta passível de mudança através de realizações de vivências de consciência corporal. Sendo assim, o objetivo foi verificar a influência da Terapia de Consciência Corporal nas variáveis: percepção da consciência corporal, nível de ansiedade e depressão em professores de uma escola da rede pública da cidade de Presidente Prudente.

\section{METODOLOGIA}

Participaram do presente estudo 11 professores da rede pública, adultos, saudáveis, de ambos os gêneros, os quais foram submetidos a uma avaliação pré e pós 12 sessões de Terapia de Consciência Corporal (TCC), utilizando o Questionário de Consciência Corporal e a Escala de 
Ansiedade e Depressão Hospitalar (HAD). A documentação foi aprovada pelo Comitê de Ética e Pesquisa (CEP) com o número 113/2010.

As vivências de consciência corporal foram realizadas sob comando verbal, com voz suave e pausada para que houvesse maior percepção das sensações corporais. Estas tem objetivo de melhorar a consciência do corpo através da experiência sensorial. Além disso, foram trabalhados: equilíbrio, flexibilidade, coordenação, reeducação respiratória, socialização, propriocepção, relaxamento e coordenação motora. Durante as sessões de consciência corporal, foram utilizados materiais variados como bastão, bolinha de tênis e cunha de espuma entre o corpo e o colchonete, em regiões diversas do corpo como nos pés, escápulas, coluna e região sacral. Tomando consciência do corpo, despertamos ferramentas internas para o combate de dores e para o desenvolvimento de posturas e atitudes que melhoram nossa qualidade de vida e até o relacionamento interpessoal.

A percepção corporal foi mensurada pelo questionário de Consciência Corporal (Shields, Mallory \& Simon 1989) que contém 18 questões que pontuam de 1 (resposta negativa) a 7 (resposta positiva) de acordo com a relação que cada indivíduo tem com o seu próprio corpo. Somando o resultado assinalado nas 18 questões, obtém-se um escore que demonstra o nível de consciência corporal de cada indivíduo. Quanto mais respostas 'totalmente verdadeiras', maior nível de consciência corporal, e quanto mais respostas 'de jeito nenhum', menor será o nível de consciência corporal. A resposta será expressa em porcentagem. O cálculo será realizado diretamente por meio do link: http://www.fortrefuge.com/quiz-Body-Awareness.php

O HADS é constituído por quatorze itens, sendo sete destes orientados para a avaliação da ansiedade (HADS-A) e os restantes sete para a depressão (HADS-D). A escala de medida é de 4 pontos, 0-1-2-3, podendo atingir 21 pontos cada escala. (Zigmond \& Snaith-1983) recomendam como ponto de corte para ambas as subescalas $\geq 9$. Segue-se o significado atribuído às pontuações em ambas as escalas: HAD-ansiedade/depressão: sem ansiedade de 0 a 8, com ansiedade $\geq 9$; HAD-ansiedade/depressão entre "8" e "10" "leve", HAD-ansiedade/depressão entre "11" e "14" moderada; HAD- ansiedade/depressão entre "15" e "21" "grave".

\section{RESULTADOS}

Os participantes foram avaliados antes e depois das terapias de consciência corporal. Observou-se que todos os professores alcançaram melhora na percepção da consciência corporal após a intervenção (Tabela 1). 
Tabela 1. Valores, em média da percepção consciência corporal.

\begin{tabular}{c|cc}
\hline & \multicolumn{2}{|c}{ Percepção consciência corporal } \\
\hline Professores voluntários & Antes & Depois \\
& $61,72 \pm 14,07$ & $77 \pm 14,06$ \\
\hline
\end{tabular}

Os resultados da avaliação dos sintomas de ansiedade e depressão, utilizando-se a Escala HAD, podem ser observados na Tabela 2. Nesta avaliação não houve uma melhora significativa, pois quando o questionário foi reaplicado os professores estavam em época de provas e exames de alunos ocorrendo assim uma interferência no resultado final.

Tabela 2. Valores, em média da avaliação da escala HAD.

\begin{tabular}{c|cccc}
\hline & \multicolumn{2}{|c}{ Antes da intervenção } & \multicolumn{2}{c}{ Depois da intervenção } \\
\hline \multirow{2}{*}{ Professores voluntários } & Ansiedade & Depressão & Ansiedade & Depressão \\
& $9 \pm 2,48$ & $7,63 \pm 2,87$ & $8,72 \pm 3,40$ & $6,63 \pm 3,61$ \\
\hline
\end{tabular}

\section{DISCUSSÃO}

Este estudo investigou e identificou que os professores são submetidos ao estresse físico e psíquico ao confrontar-se com situações desfavoráveis de sua profissão. Os descritos apontam uma repercussão negativa sobre sua saúde, não significando necessariamente adoecer, mas apresentar incômodos físicos e emocionais gerados por uma sobrecarga de trabalho, podendo vir a comprometer o convívio e interação no ambiente escolar. Hoje, no trabalho docente, estão presentes aspectos potencialmente estressores, como baixos salários, escassos recursos materiais e didáticos, classes superlotadas, tensão na relação com alunos, excesso de carga horária, inexpressiva participação nas políticas e no planejamento institucional (BENEVIDES-PEREIRA et al., 2003).

As variáveis demonstram que há um intenso mal-estar entre os docentes devido à insegurança, angústia, tensão, esgotamento, irritabilidade, insatisfação, ansiedade, desesperança e estresse impressos pelo ambiente profissional. Este estudo, da oportunidade para que os professores percebam os fatores mais prejudiciais em sua profissão e, a partir daí, possam aprender técnicas para minimizá-los. De acordo com (Reich, 1995), o professor que está sintonizado com seu corpo, pode despertar maior prazer em ensinar e se relacionar melhor com seus alunos, além de melhorar seu fluxo de energia, evitando que situações frustrantes se reflitam em tensões em seu corpo. 
Entendemos que o docente precisa sentir-se inserido na sociedade, ser mais realista em suas expectativas e limitações quanto ao âmbito escolar e sua realidade atual, e não permitir que os obstáculos cotidianos interfiram em sua saúde e diminuam sua qualidade de vida.

\section{CONCLUSÃO}

Obtivemos como conclusão, um resultado positivo frente à realização das sessões de terapia de consciência corporal. Todos os participantes do estudo apresentaram uma melhora significativa nas percepções e em sua consciência corporal. Quanto à ansiedade e depressão, houve uma ligeira melhora, porém, não houve resultado significativo para o estudo.

\section{REFERÊNCIAS}

1. CARLOTTO, M. S.; PALAZZO, L. S. Síndrome de burnout e fatores associados: um estudo epidemiológico com professores. Cadernos de Saúde Pública, Rio de Janeiro, v. 22, n. 5, p. 1.0171.026, 2006.

2. CARLOTTO, M. S.; Síndrome de Burnout em Professores: Prevalência e Fatores Associados. Psic.: Teor. e Pesq., Brasília, Vol. 27 n. 4, pp. 403-410, Out-Dez 2011.

3. DEJOURS, C., ABDOUCHELI, E. Itinerário teórico em psicopatologia do trabalho, In: DEJOURS, Cristophe, ABDOUCHELI, E., JAYET, C.. Psicodinâmica do trabalho: Contribuições da escola dejouriana à análise da Relação: prazer, sofrimento e trabalho - São Paulo: Atlas, 1994.

4. ARAÚJO, T. M.; SENA, I. P.; VIANA, M. A.; ARAÚJO, E. M. Mal-estar docente: avaliação de condições de trabalho e saúde em uma instituição de ensino superior. Revista Baiana de Saúde Pública; v. 29, n. 1, p. 06-21, 2005.

5. SMITH, E.; LEMKE, J.; TAYLOR, M.; KIRCHNER ,L.; HOFFMAN, H. Frequency of voice problems among teachers and others occupations. Journal of Voice, 1998; v. 12, n. 4, p. 480-488. In ASSUNÇÃO, A da A. Saúde e mal-estar do(a) trabalhador(a) docente. VII Seminário redestrado nuevas regulaciones em América latina Buenos Aires, 3, 4 Y 5 de Julio de 2008.

6. PEREIRA, M.J.; SANTOS, T.M.M.; VIOLA, I.C. Influência do ruído em sala de aula sobre a performance vocal do professor. In: FERREIRA, L. P.; COSTA, H. O. Voz ativa: falando sobre o profissional da voz. São Paulo: Roca, 2000, cap. 4, p. 57-77. In ASSUNÇÃO, A da A. Saúde e malestar do(a) trabalhador(a) docente. VII Seminário redestrado - nuevas regulaciones em América latina Buenos Aires, 3, 4 Y 5 de Julio de 2008.

7. SIMÕES, M.; LATORRE, M. R. D.; BITAR, M. R. Uso profissional da voz por educadores de creches: achados preliminares. Revista da Sociedade Brasileira de Fonoaudiologia; 2000; v. 5, n.7, p. 28-35. In ASSUNÇÃO, A da A. Saúde e mal-estar do(a) trabalhador(a) docente. VII Seminário redestrado - nuevas regulaciones em América latina Buenos Aires, 3, 4 Y 5 de Julio de 2008.

8. DUFFY, O. M.; HAZLETT, D. E. The impact of preventive voice care programs for training teachers: a longitudinal study. Journal of Voice 2004, v. 18, n. 1, p. 63-79, 2004. In ASSUNÇÃO, A 
da A. Saúde e mal-estar do(a) trabalhador(a) docente. VII Seminário redestrado - nuevas regulaciones em América latina Buenos Aires, 3, 4 Y 5 de Julio de 2008.

9. BENEVIDES-PEREIRA, A. M. T. MBI \&- Maslach Burnout Inventory e suas adaptações para o Brasil. In: REUNIÃO ANUAL DE PSICOLOGIA, XXXII, 2001, Rio de Janeiro. Anais... Rio de Janeiro: [s.n.], 2001. p. 84-85. In VANIA, M; MARY, S. C.; SHEILA, C. Síndrome de Burnout e estratégias de enfrentamento em professores. Arq. bras. psicol. v.60 n.1 Rio de Janeiro abr. 2008.

10. HARRISON, B. J. Are you to burn out? Fund Raising Management, 30(3), 25-28. 1999.

11. GIL-MONTE, P. R. El síndrome de quemarse por el trabajo (burnout) como fenómeno transcultural. Informació Psicológica, 91-92, 4-11. 2008.

12. REICH, W. Análise do caráter. 2. ed. São Paulo: Martins Fontes, 1995. In MOYZÉS, M. H. F. O despertar da consciência corporal do professor. Uberlândia, Ano VII, n. 7, p. 57-71, 2006.

13. MOYZÉS, M. H. F, MOTA, M. V.S. Sensibilização e conscientização corporal do professor. In CONVENÇÃO BRASIL LATINO AMÉRICA, CONGRESSO BRASILEIRO E ENCONTRO PARANAENSE DE PSICOTERAPIAS CORPORAIS. 1., 4., 4., Foz do Iguaçu. Anais... Centro Reichiano, 2004.

14. SHIELDS, S.A., Mallory, M.E., \& Simon, A. (1989). The Body Awareness Questionnaire: Reliability and validity. Journal of Personality Assessment, 53, 802-815. http://dx.doi.org/10.1207/s15327752jpa5304 16

15. ZIGMOND AS, SNAITH RP - The hospital anxiety and depression scale. Acta Psychiatr Scand, 1983;67:361-370. http://dx.doi.org/10.1111/i.1600-0447.1983.tb09716.x 